\title{
The Power of Words in Tension: Enterprise/Strategy as a Dilemma in Neoliberalism's Persistence.
}

Brendan O'Rourke

Technological University Dublin, brendan.orourke@tudublin.ie

Follow this and additional works at: https://arrow.tudublin.ie/buschmarcon

Part of the Entrepreneurial and Small Business Operations Commons, and the Strategic Management Policy Commons

\section{Recommended Citation}

O'Rourke, B. K. : The power of words in tension: enterprise/strategy as a dilemma in neoliberalism's persistence, 74th Annual Meeting of the Academy of Management August 1st to August 5th 2014, Philadelphia, USA.

This Conference Paper is brought to you for free and open access by the School of Marketing at ARROW@TU Dublin. It has been accepted for inclusion in Conference papers by an authorized administrator of ARROW@TU Dublin. For more information, please contact arrow.admin@tudublin.ie, aisling.coyne@tudublin.ie, gerard.connolly@tudublin.ie.

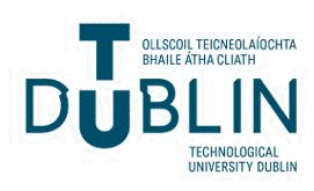


Electronic Submission ID: 16601

The power of words in tension: enterprise/strategy as a dilemma in neoliberalism's

persistence.

Paper for $74^{\text {th }}$ Annual Meeting of the Academy of Management August $1^{\text {st }}$ to August 5th 2014, Philadelphia, USA.

Dr. Brendan K. O'ROURKE,

Research Fellow, School of Marketing,

College of Business, Dublin Institute of Technology,

Aungier St., Dublin 2, IRELAND

Tel. +353-1-4027097

Email brendan.orourke@dit.ie 
Electronic Submission ID: 16601

\begin{abstract}
We address how enterprise is related to, another important discourse, strategy. From a discourse analysis of the talk of small firm owner-managers, emerges a view of strategy and enterprise as a single, integrated entity, bound together by some commonalities but more importantly by paired opposites reminiscent of ideological dilemmas (Billig, Condor, Edwards, Gane, Middleton \& Radley, 1988). This dilemmatic nature of enterprise/strategy discourse adds to explanations for the persistence of the neoliberal form of enterprise, with the entrepreneur as the heroic saviour of all, based on the entrepreneur as an empty signifier (Jones \& Spicer, 2009; Kenny \& Scriver, 2012) or as a spectre (Marttila, 2012).
\end{abstract}

Key words: enterprise, entrepreneur, strategy, discourse analysis, ideological dilemma, neoliberalism. 
Electronic Submission ID: 16601

\section{INTRODUCTION}

Talk of the entrepreneur in its modern sense appeared with the emergence of capitalism in the Europe of the 1700s, and remains central to understanding the economy today. Corporate strategy emerged as large non-owner managed firms became economically important (Knights \& Morgan, 1991). For a time, strategy substituted for the earlier enterprise discourse especially when discussing large non-owner managed corporations. The discourses of strategy and enterprise developed as separate academic areas and as logics of two very different economic domains. However with the ascent of neoliberalism from the late 1970s, large organizations (Kanter, 1983: 27) and governments have been urged to be more entrepreneurial (Klein, Mahoney, McGahan, \& Pitelis, 2010; Osborne \& Gaebler, 1993). Meanwhile, small firms were encouraged to be more strategic (Kraus, Harms, \& Schwarz, 2006). Indeed the dominant model of an entrepreneur is one that "converts his [sic] individual and social goals into organizational strategies" (da Costa \& Silva Saraiva, 2012: 605). Neoliberalism insists on strategy and enterprise having an intimate relationship.

How should we now understand the relationship between these discourses? This article examines how strategy and enterprise discourse are related in the talk of practitioners, entrepreneurs in small owner-managed firms. What emerges is a view of strategy and enterprise as a single integrated entity, bound together by some commonalities but more importantly by paired 
Electronic Submission ID: 16601

opposites reminiscent of ideological dilemmas (Billig et al., 1988). What is now the nature of the relationship between strategy and enterprise discourse? This is important not only to understand how these academic fields are related in practice, but also because discourses do not merely describe but constitute subjects and objects (Mumby, 2011).

We address the relationship between strategy and enterprise by next looking at the academic literature on the features, both shared and individual, of enterprise and strategy. This is followed by outlining the context in which we explored the empirical relationship between strategy and enterprise. We then provide an analysis on some data with illustrative interview extracts interpreted in detail. This interpretation gives rise to a metaphor for understanding of the interaction of strategy and enterprise discourses. Finally we conclude with a discussion of the implications of this metaphor for study of strategy and enterprise.

\section{THE DISCOURSES OF STRATEGY AND ENTERPRISE}

Though entrepreneurs can be recognized across the ages (Drakopoulou -Dodd \& Gotsis, 2007), Hayek (1986:226) credits the French-Irish economist and businessman, Richard Cantillon, with introducing the term entrepreneur in its modern sense to $18^{\text {th }}$ century Europe. As Hébert $\&$ Link (2006:18) point out, “social standing was practically irrelevant to Cantillon's notion of entrepreneurship". Cantillon's entrepreneur therefore represented a break with the established order of inherited tradition and property and his stress on economic function rather than social 
status remains attractive and liberating. Towards the end of the $19^{\text {th }}$ century, the rise of the great corporation, the separation of its management from its ownership and the recognition that controlling these large corporations requires the visible hand of the professional manager (Chandler, 1962) gave rise to the discourse of corporate strategy (Knights \& Morgan, 1991:258). At one extreme, there was even talk of enterprise being in its 'death struggle' and at the other extreme microeconomics' theory continued as if nothing had changed (Bögenhold, 2000). Prior to the rise of neoliberalism in 1970s, the general consensus after 1945 was that expressed by that most representative of Keynesians of his time, John Kenneth Galbraith who felt that there were now two sectors - one entrepreneurial and one corporate in the post-1900 economy (Kreisler, 1986). Strategy and enterprise were alternatives to be used in very different contexts: they were, to borrow a metaphor, two distinct and non-overlapping magisteria (Gould, 1997).

Yet since the loss of faith in strategic planning in 1970s, this bipolar application of these models of economic governance, whereby large organizations were subject to the logic of strategy and smaller firms are subject to the logic of enterprise, have been conflated in the dominant discourse of neoliberalism. Large organizations, including public ones, have been urged to become more entrepreneurial (Osborne \& Gaebler, 1993). Small firms, meanwhile, have been the subject of policy that has required them to be more strategic (Perren \& Jennings, 2005). With neoliberalism, enterprise and strategy no longer have clearly separate domains. Yet the academic disciplines of 
Electronic Submission ID: 16601

enterprise and strategy have generally remained quite distinct. For that reasons these two discourses are, in this article, initially examined separately below.

\section{Characteristics of enterprise discourse}

Enterprise discourse is holistic, concerned as it is with expressing an overall grasp of the situation. Kanter (1983:27) "found that the entrepreneurial spirit producing innovation is associated with a particular way of approaching problems that I call 'integrative'.” Enterprise demands "stitching together a variety of stakeholder commitments" into an integrated whole, even if "neither entrepreneurs nor their stakeholders had quite articulated a coherent vision of the market until after it came to be" (Sarasvathy \& Venkataraman, 2011:120).

The entrepreneur is masterful: "he (sic) bridges worlds, bends time with an 'unquantifiable, limitless' impact on the world around him" (Nicholson \& Anderson, 2005:161). Nicholson and Anderson's (2005) use of the masculine pronoun is deliberate, for entrepreneurial identity, at least in mythic terms is male (Duberley \& Carrigan, 2013).

The entrepreneur is an optimist (Carr, 2000a), and is "dripping with enthusiasm" (Nicholson \& Anderson, 2005:161). That such optimism may reach levels that become dysfunctional, does not take away from the general optimism of entrepreneurs (Hmieleski \& Baron, 2009). 
Electronic Submission ID: 16601

The entrepreneur is also resolute. Success results only because they are "persistent, almost pig-headed visionaries at that, steadfast in the single-minded pursuit of their vision" (Sarasvathy \& Venkataraman, 2011: 120). Most entrepreneurs, seemingly, "are totally dedicated to their business, sometimes at considerable cost to their relationships with friends and families. They work tirelessly" (Bygrave, 2004:5-6).

Enterprise discourse is individualistic. There is stress on the unaccountable individual and the independent pursuit of that particular person's goals (Hendry, 2004: 55). Enterprise has, in place of accountability, "the values of individualism, personal achievement, ambition, striving for excellence, effort, hard work and the assumption of personal responsibility for actions" (Chell, 2007: 8). Enterprise discourse ties in with a broader ethic “... of the enterprising self: work on yourself, improve the quality of your life, emancipate your true self, eliminate dependency, release your potential" (Rose, 1992:152-153).

Enterprise disrupts. For Schumpeter (1976), enterprise is the creative wave so destructive of those who wish for a quiet life of no change. Such a settled existence is not for the hero of the enterprise discourse, for the "the creation and intentional pursuit of entrepreneurial ideas lies at the core of the domain of entrepreneurship" (Hayton \& Cholakova, 2012: 41). The creativity of entrepreneurship "can be characterised by stretching or even breaking the rules of convention" (Fillis \& Rentschler, 2010:51). 
Electronic Submission ID: 16601

Enterprise is creative (Hjorth, 2002). In a pan-European study of entrepreneurial metaphors, the archetype of the entrepreneur as characterized "by the creation of new ideas" is one of broadly four-part social construction of the entrepreneur' (Anderson, Drakopoulou -Dodd, \& Jack, 2009: 5). More generally few would disagree that the "creation and intentional pursuit of entrepreneurial ideas lies at the core of the domain of entrepreneurship" (Hayton \& Cholakova, 2012:41).

Risk-taking is another essence of the enterprise discourse. Entrepreneurs push beyond the comfort zone of competence, into risk and uncertainty and "always operate at the edge of their competence, focusing more of their resources on what they do not yet know (e.g. investment in $\mathrm{R}$ \& D) than on controlling what they already know" (Kanter, 1983:27). Even if the reality maybe different, conventionally the entrepreneur is a risk-taker (Hytti, 2005), and those surveying the literature report that though "there is no single agreed definition of entrepreneurship... most definitions include elements of risk-taking..." (White, Thornhill, \& Hampson, 2006:24).

While there is indeed no single definition of enterprise, being risk-taking, creative, disruptive, individualistic, holistic, masterful, positive and resolute are all qualities that we associated with enterprise. As we will see below some of these qualities enterprise discourse shares with strategy but there are also attributes of strategy discourse are different. 
Electronic Submission ID: 16601

\section{Characteristics of strategy discourse}

A key characteristic of strategy discourse, one it shares with enterprise discourse, is its holistic nature. For example, Hendry ( 2000:970) notes: "Strategic discourses are characterized by a generality that is absent from discourses associated with the functional areas of management ..." . This holistic view means that strategy "can identify, formulate and communicate one stable common goal that the entire organization should reach" (Clegg, Carter, \& Kornberger, 2004:24). Strategy discourse is “...inspirational and unifying...” (Cornut, Giroux, \& Langley, 2012: 44), allowing the organization to be treated and directed as one.

Like enterprise discourse, strategy discourse is masterful in the sense that it implies an active, powerful, intentional masculine agent who drives and shapes the world (Knights \& Morgan, 1991:267 ; Liedtka, 1998:123). Strategy stresses direction (Barry \& Elmes, 1997; SamraFredericks, 2003), rule-following (Ansoff, 1968:106), and hopes to steady the organization through stormy waters. Since strategy is about setting direction for the whole organization there must be a certain passivity in the organization (Clegg et al., 2004:22). If the organization is portrayed as passive in its willingness to be shaped by strategy, then strategy and those who wield it are masterful.

Optimism seems, too, to be as central to strategy discourse as it is to enterprise. There is a “... 'grand narrative of progress' that is inherent within mainstream accounts of strategy ...” (Grandy \& Mills, 2004: 1157-1158). This optimistic element of strategy discourse can function 
in strategists' accounts of their stewardship of organizations, evidenced, for example, in the 'Pollyanna effect' in company reports following disappointing company performance (Rutherford, 2005) and in the positivity characteristic of the genre (Cornut et al., 2012).

In common with the entrepreneur, the strategist must be resolute. Porter (1996:77) refers to the strategist being subject to "constant pressures to compromise, relax trade-offs, and emulate rivals". While disagreeing with Porter on many issues, Mintzberg (1973:29) characterizes the life of the manager as one of "much work at unrelenting pace". The strategist must be dedicated enough to get up and act, if not feel, like a strategy machine (Clegg et al., 2004).

While strategy and enterprise discourses are both described as holistic, masterful, positive and resolute there are attributes of strategy that show their differences as well as their similarities.

Unlike enterprise, strategy is not an individualized affair, but rather its logic has the collective and the corporate at its center (Crouch \& Basch, 1997). Thus it is no surprise that, as a genre strategy "...plans draw people together with more words referring to commonality than any other corpus, again suggesting the importance of expressing collective consensus and collaboration" (Cornut et al., 2012:45), allowing, for strategic plans a "we-intrepretation”, (Pälli, Vaara, \& Sorsa, 2009: 309).

Whereas enterprise celebrates being disruptive, strategy discourse developed to legitimate the power of professional managers for "where the absence of property rights may generate crises of legitimacy for managers, the development of strategy within the corporation can have the effect of sustaining a new basis of managerial prerogative” (Knights \& Morgan, 1991: 263). 
Electronic Submission ID: 16601

Strategy documents use self-legitimation features (Pälli et al., 2009: 308) to became authoritative and directive and this is “... a typical characteristic of the strategy genre” (Vaara, Sorsa, \& Pälli, 2010: 690). From the literature on strategy discourse, it quickly becomes apparent that strategists' use of power must be rationalized and explained. Accountability is a key feature of this discourse, for as Knights \& Morgan (1991:258) stress strategy discourse emerged to fill a gap where "... a discursive space has opened up - the corporation has to explain what it is doing and why it is doing it."

In order to act as a discourse that can explain professional management action, strategy must - at least in its traditional forms - make the most of "its roots in rationalist reference points (i.e. logic, objectivity, technique) and abstractions (i.e. modeling, simplification)" (Grandy \& Mills, 2004: 1157). Strategy’s language is therefore analytical in nature (Crouch \& Basch, 1997), and, drawing on disciplined rationalities of the academy " strategy applies a knowledge of economics and the social scientists, of specific industries and markets, and of the organization's resource capabilities to the creation of economic value and wealth" (Hendry, 2000:969).

Strategic decision-making is the way risk and uncertainty is managed, or at least thought as being managed, in the modern organization (Miller, 2009:165). Strategy is “... the means of transforming uncertainties in the environment into calculable risks" (Knights \& Morgan, 1991:270). From the start this activity, of "attaching some estimate or risk to the discernible 
Electronic Submission ID: 16601

alternatives" (Andrews, 1997: 53), has been recognized as a key to the logic of strategy. For the strategist, uncertainty must be transformed into risk and risks are managed on the basis of analysis and planning.

\section{The unclear relationship between strategy and enterprise}

While there seems to be much agreement amongst academics on the features of enterprise and strategy as individual discourses, there is less agreement on how they interrelate. Knights \& Morgan (1991:260) clearly contrast enterprise and strategy discourse when they write: “... managers may cling to some sort of entrepreneurial ideology in which conformity to the "top down' demands of a strategic plan are anathema." Those promoting enterprise in large organizations do seem to agree that this implies a revolution in the traditional strategic control of organizations (Kanter, 1983; Osborne \& Gaebler, 1993). On the other hand, enterprise and strategic discourses do seem at times to go together (Carr, 2000b). Perhaps enterprise incorporates strategy as an element of it, as Carr (2000a:99) seems to suggest. Alternatively, perhaps it is strategy that can encompass all the features of enterprise: For example, Heracleous, (2003) argues strategy can become creative. Perhaps the combination of enterprise and strategy can become something new that is a narrower version of both (Armstrong, 2005:217).

There is, therefore, a variety of views on the relationship between strategy and enterprise discourse. A priori it seems possible that, as neoliberalism implies, they overlap harmoniously in a coherent and consistent ideology. It is also possible that one might drive out the other, with 
perhaps one of the discourses seen as in error, as irrelevant or merely as a straw man which shows the superiority of the other. It is possible that one discourse might be used to incorporate the other. There are numerous possibilities and this research aims to carefully examine the discourse material chosen so as to add to knowledge on this issue. The empirical question then is how are the discourses of strategy and enterprise used in relation to each other in the talk of practitioners?

\section{THE EMPIRICAL CONTEXT}

A suitable context in which to illustrate practitioner use of strategy and enterprise discourses and the how they might be interrelate can be found in form of the owner-managed small young firms of the business magazine sector in late Celtic-tiger (2000-2007) Ireland. Whereas young small firms offer a context where the original condition (non-owner management) for the emergence of strategic discourse is less likely to be present, small-firm owner managers are likely, from a rationalist perspective, to seek the results that strategy promises. Although enterprise has drifted far from its mythical origins in the discussion of firm formation, the small and young firm remains central to enterprise discourse. Small and young firms are therefore also a likely source of enterprise discourse. Ireland too provides an interesting site, given the influence of both Anglo-American and more mainland European influences on its business practices (Kenny \& Scriver, 2012; O'Rourke, 2010). The general business magazine is a suitable sector for a number of reasons. In the first place the magazine industry is particularly strategically challenging as it faces great technological change (Cox \& Mowatt, 2008) and a complex supply chain (Wirtz, 
Electronic Submission ID: 16601

2011). Secondly, the magazine sector is thought to be a particularly entrepreneurial environment (Commission of the European Communities, 2005: 73). A third reason to choose the sector is the likely familiarity, with the strategy and enterprise discourses of those involved with business magazines: as business magazines are a key distributor of business discourses (Van der Wurff, 2005: 143).

We chose researcher-involved interviews to generate the empirical material. An interview is more of a complete interaction, a single event that is discrete and bounded in time than other interactions. The trick to the use of the researcher-involved interview in discourse analysis is to harness the insight that “... discursive mediation should not be viewed as a source of contamination but rather as a crucial source of insights into both interviewing processes and the social worlds they seek to document" (Briggs, 2003: 496). Both researched and researcher, know a lot about the nature of the interview and how to use it. If an interviewee wishes to say a number of things, all of which depend on each other, the interviewee has a reasonable idea of the time available to balance out the intended discourse. Such completeness in interaction is particularly useful in examining at the relationship between two discourses.

From the variety of discourse analytical approaches a method most appropriate to this question is in the tradition of those who combine an attention to the detailed nature of interactive data with 
a sensitivity to the wider context to build data-constrained interpretations (Whittle \& Mueller, 2011).

\section{EMPIRICAL ENTERPRISE/STRATEGY TALK}

\section{An overview of the data}

In late Celtic-tiger Ireland (2000-2007) there were 19 publishers involved in general business magazines. Company websites, annual accounts, media coverage and industry informants were consulted in an effort to understand the industry. To examine the interaction of enterprise and strategy discourse the first formal interviews with the "lead entrepreneur" (Ensley, Carland, \& Carland, 2000) of companies in existent less than five years were focused on. Only formal interviews were used as they gave a greater opportunity for the interviewee to control the overall impression created. The 'lead entrepreneur' of each firm was selected because strategy is the language of leaders (Clegg et al., 2004: 23) and because preliminary analysis of other interviews we found that the 'lead entrepreneur' was frequently deferred to. All the 'lead entrepreneurs' had been founders, were the biggest shareholders in the company, were the highest ranking managers of the organizations concerned and, using other interviews as a resource, were spoken of as the leader or the boss.

Such a focused set of empirical material cannot claim to tell us much about the distribution of discourses in any population general enough to be of enduring interest. However this data can demonstrate how strategy and enterprise discourse are used in these interactions. Furthermore the 
focused nature of the data means that the interpretation offered here has been disciplined by the confined nature of data, as with this limited data it is hard to ignore bits of data that challenged the coherence of any proposed interpretations.

\section{An interpretation}

Across these interviews there was a lot of variability in the use of enterprise and strategy discourse, for example in how these discourses were used in relation to other discourses such as those of being a professional. More relevant here was the way in which the enterprise and strategy discourses seemed to act in concert, in particular how the rising of strategy discourse always seemed to be balanced by a subsequent decline in that discourse together with a compensating rise in enterprise discourse, and vice versa. Below this pattern is illustrated, here of how an initial rise of enterprise discourse is followed by a rise of strategy discourse to replace it. The data is more extensively detailed in [A reference to this source available through the internet is excluded to facilitate blind review], but here we focus on a single interview. The various symbols in the transcript are based on Jeffersonian transcription (Atkinson \& Heritage, 1984) and the particular meanings attached to the symbols here are specified in Appendix A.

The interviewee here called, Una is the founder and owner of a small publishing business magazine, which was about four years old at the time. An email sent to Una prior to the interview declared that the research was 'on strategic thinking' that involved 'unstructured interviews with 
Electronic Submission ID: 16601

directors of small to medium-sized enterprises.' The interviewee lasted a total of 76 minutes and involved over 700 turns.

Extract I presents a section in the interview where enterprise talk is dominant. 
Electronic Submission ID: 16601

EXTRACT I From an interview between Una and Researcher

34 Una: ... I was given some contact management software to play with by a friend of mine and it was a revelation to me at that time that you could put together a web site and not have to handwrite every page

35 Researcher: Yeah sure.

36 Una: that it would populate an archive and sort things and um, you know, have a rolling headlines on the

37 Researcher: Ah okay

38 Una: front page and everything. Um so that's how I started with TronCom and the business kind of

39 Researcher: Yeah and did that, was that an intimidating start for you? You had been a kind of employ- employee if you like, you were working as a journalist and you were going into being a journalist entrepreneur or manager or whatever you, business person(.)[was that

40 Una: I was] never of an employee anywhere, I was always on my own.

41 Researcher: Okay.

Source: Transcript from 76-minute interview between 'Una' and Researcher [A reference is to a work available through the internet is excluded to facilitate blind review of this article]. 
Electronic Submission ID: 16601

Una attributes the start of her company (here named TronCom) to her being 'given contact management software to play with' (Turn 34). This not only signals the creative, playful element of enterprise talk (Hjorth, 2002: 65) but also illustrates Una's ability in being so casually able to grasp such technological skills. In Turn 39, in an effort to give some space for Una to discuss any difficulties that she might have encountered in becoming a manager, the researcher inadvertently but usefully stimulates Una to point out how autonomous she has been in her career when she declares : "I was] never of an employee anywhere, I was always on my own" (Turn 40). This is quite an assertive correction by Una: her statement starts before the interviewer's turn finishes and she focuses on correcting the error though it had been stated in a mitigated way ("You had been a kind of employ- employee if you like, you were working as a journalist", Turn 39). Here, Una is asserting an autonomy of the sort associated with enterprise (Down, 2006). The assertive way this is done is somewhat in tension with the passive position of being an interviewee, and the fact that Una goes to the effort of overturning this norm of passivity shows the importance of this illustration of her autonomy. 
Electronic Submission ID: 16601

EXTRACT II From an interview between Una and Researcher

42 Una: Um and I, and I found that I worked well on my own and I didn't feel isolated working at home oth- some freelancers do

43 Researcher: Uh-huh.

44 Una: but what did feel strange was hiring another journalist to write stuff for

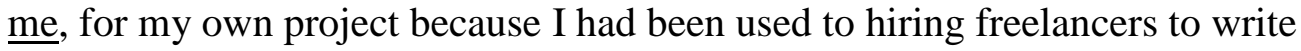
for other publications that I was editing

45 Researcher: Mm.

46 Una: as a freelance editor but what it was actually a journalist writing stuff for $\underline{\text { me }}$

47 Researcher: Mm.

48 Una: I remember having a real, having just this brainwave thinking if the website is growing, people are looking for more news on the website and I have some people who are willing to buy this newsfeed from me, but I can't write it all myself. At the same time I was writ I was writing a lot of eh analyst reports for companies on their internet strategy

49 Researcher: Right, yeah.

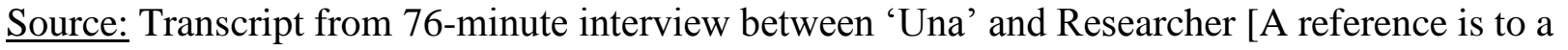
work available through the internet is excluded to facilitate blind review of this article]. 
Electronic Submission ID: 16601

The interaction shown in Extract II above follows directly from interaction of Extract I.

Returning to the more passive role of the interview Una addresses the question asked by the researcher in Turn 39 (Extract I) and acknowledges as new the increase in responsibility that came with having her own company: 'but what did feel strange was hiring another journalist to write stuff for me, for my own project because I had been used to hiring freelancers to write for other publications that I was editing (...) as a freelance editor but what it was actually a journalist writing stuff for me' (Turn 46). The fact of it being her company seems to make it more of her 'own project' - she stresses her control (note how she emphasizes and repeats 'me') - than talk of her roles as editor working for other companies. Turn 48 continues this focus on Una's personal concerns and thinking with continued use of 'I', 'me' and 'myself' as would be expected in enterprise talk (Hendry, 2004: 55) . In Turn 48, Una also describes her "brain wave": Clearly a creative disruption typical of enterprise talk (Schumpeter, 1976). As Turn 48 draws to a close and Una's entrepreneurial credentials have been well established, there is some disfluency in "I was writ I was writing" and in "a lot of eh" as more strategy language is introduced: "analyst reports" and "internet strategy".

Extract III follows almost immediately after Extract II with only ten short turns (excluded from presentation to avoid identification) separating the extracts but the shift from enterprise to strategy talk is confirmed. 
Electronic Submission ID: 16601

In Turn 60 strategy talk continues to rise while enterprise talk has gone down, as Una declares:

"But from the very beginning I want to make clear that, well what TronCom does is we publish a series of publications under our brand and under our client's brand" (Turn 60). Here the company is very much emphasized as a separate corporate entity from Una the individual: the language moves from "I" to "We", from "my project" to "our brand". The company is referred to as a separate corporate entity: "what TronCom does is" (Turn 60) and it possesses "divisions" (Turn 66). This reification of the company is what would expect from a strategy discourse that developed to provide legitimization for the professional manager (Knights \& Morgan, 1991).By using this more strategic language, Una is balancing the personal and individualized way in which the company that had been discussed in the earlier entrepreneurial talk of Extract I and Extract II. Una does this by portraying here the more formal strategic aspect of the company where some things were clear 'from the very beginning' (note that this phrase is used both in Turn 60 and in Turn 66) and where the impersonal corporation is to the fore.

The up and down pattern of enterprise discourse being replaced by strategy discourse (or in other instances vice-versa) evident in these extracts from the interview with Una was typical of Una's interview in general, and of the other interviews analyzed in this study.

\section{A modest generalization}

Taking account of the particular national, sectoral, interactional and chronological context in which these interviews were conducted it is possible to suggest a model, to serve as a modest 
Electronic Submission ID: 16601

generalization (Payne \& Williams, 2005), of how enterprise and strategy discourses are used by small-firm owner-managers. This model is presented in Figure 1. 
Electronic Submission ID: 16601

FIGURE 1 A see-saw model of Enterprise/Strategy discourse

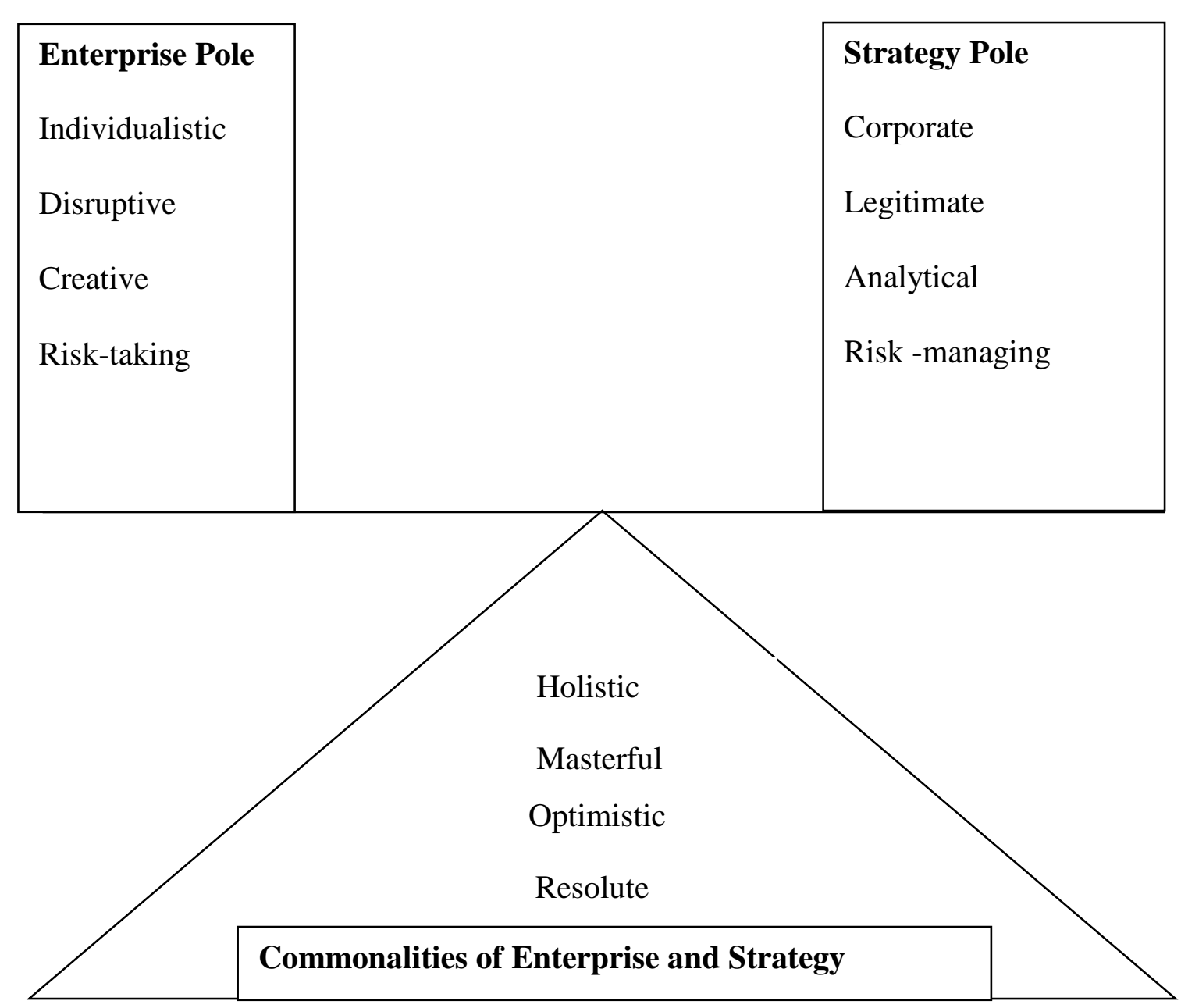


Electronic Submission ID: 16601

Figure 1 is designed to portray Enterprise/Strategy discourse as operating in a way analogous to a seesaw. The figure gives a lateral view of the basic seesaw structure. The play of the seesaw involves one child pushing up and thus the opposite child going down, followed by the action of gravity and of the opposite child taking a turn in pushing up and the first child being pushed down. Much amusement can be had in the resulting action-reaction cycle. The seesaw provides a good metaphor for the way elements of Enterprise/Strategy discourse were found to operate in this research: when particular elements of enterprise discourse were raised in an interviewee's talk, they would then decline to be replaced by the raising of a matching 'opposite' of strategy discourse. As with the seesaw, strategy and enterprise discourses, even when going in opposite directions, seem to operate as part of the same structure. The enterprise and strategy discourses certainly share some elements in common, which are portrayed in Figure 1 as being analogous to the base that forms the triangular base of the seesaw. However, there are also elements of the strategy and enterprise discourses that seem, like the seesaw, to move in opposite directions, and invoke their opposite in response.

Note how the seesaw works as an analogy better than, say, an elastic band: the response of a rise in enterprise talk is not to snap back into shape but rather to evoke an almost opposite response in the strategy pole. The precarious nature of the seesaw also highlights the fact that the roles that small-firm owners are often asked to play can result in them experiencing discomfort if these roles are not kept in the required balance. Such owner-managers can find themselves like a child 
Electronic Submission ID: 16601

hitting the ground hard, then being flung into the air (with the accompanying exhilarating and/or frightening feelings and the danger of a rough landing) if the work is applied in an unbalanced way.

While the poles of the seesaw are where all the action happens, the base as the fulcrum plays a vital role. So it is with Enterprise/Strategy discourse. Since the up and down between the enterprise and strategy poles generates the discourse, it is all down to the firm foundation of the common elements of Enterprise/Strategy that have been built and are further secured during the interaction.

The seesaw analogy is also useful in that it highlights that to keep the whole Enterprise/Strategy seesaw moving requires work on both sides. This work can result in mere amusement, as in the seesaw as a plaything. However, the Enterprise/Strategy seesaw is more like those seesaws that are put to work converting the up-down forces generated by the activity at their poles to drill wells, pump water and generate electricity. The work of the Enterprise/Strategy seesaw that can be seen in the detailed analysis of the interviews included the generation of plausible roles for owner-managers; the positioning of employees, other directors and outsiders in relations with the owner-manager; the justification of value distribution, and the representation of the societal function of the firm concerned. 
Electronic Submission ID: 16601

There are, of course, ways in which the Enterprise/Strategy seesaw is not like a seesaw. Indeed the machine metaphor of the seesaw is somewhat at odds with the general metaphor at work in discourse analysis. In contrast to the seesaw, each interviewer often provided the work required at both ends of the Enterprise/Strategy pole, alternating between ends during the interview. At times the researcher provided counterweight, but generally the up-and-down movement was between elements of the talk rather than between individuals. The seesaw analogy also breaks down in so far as the individual elements that make up the poles of enterprise and strategy seem to have links to particular elements in their polar opposite For example, talk of risk-managing seems to provoke not only enterprise talk in general but, of risk-taking in particular as this seems to be its particular polar opposite.

\section{CONCLUSIONS}

Our work has important implications for how we understand the relationship between strategy and enterprise, and our model of that understanding contributes to explanation of the 'strange non-death of neoliberalism (Crouch, 2011) and its particular articulations of enterprise, with its hero of the all-saving entrepreneur, even through times of crises (Kenny \& Scriver, 2012; Marttila, 2012; O'Rourke \& Hogan, 2013).

Our work contributes too by expanding understanding of the link between the operation of strategy discourse and that of enterprise discourse. (Barry \& Elmes, 1997: 430) remark: “... it seems that entrepreneurs and senior executives tell very different tales". However, we have seen 
Electronic Submission ID: 16601

how a small-firm owner manager, an entrepreneur, incorporated the strategy discourse that originally emerged for big-firm senior executives, into her Enterprise/Strategy talk. It is clear that, at least sometimes, it is profitable to view strategy and enterprise as part of a single discourse. Clearly this was evidenced in this work in the context of small firms, but, given the increased stress on enterprise in larger organizations, the lesson might be extended.

The notion of the ideological dilemma (Billig et al., 1988) is central to this understanding of, Enterprise/Strategy as a dilemma. The importance of dilemmas and paradoxes is not unknown in the discussion of strategy. Quinn (1988: xv) attempted to move both management practitioners and academics “... closer to an understanding of the paradoxical dynamics that underlie effectiveness, mastery, and excellence”. Pitt (1998) examined the dilemmas at the heart of particular personal theories of action. This work supports Pitt and others, in their celebration of paradoxes. However, there are differences in the way dilemmas are seen to work here. For example, the dilemmas here are not, in contrast to Pitt's, seen as '... what the individual sees as a logical and intractable opposition ...' (Pitt, 1998: 397). The importance of the insight that individual thinking may be characterized by polar opposites is not disputed. However what is highlighted here is the constructive work done through dilemmas available as part of the socially available discourses of strategy and enterprise. While the individuals used the dilemmas highlighted in their talk, these dilemmas were treated less as core personal beliefs of the individual than as the up and down rhythm that moved the talk along. In particular, what this 
Electronic Submission ID: 16601

work illustrates is the productive power of dilemmas in a discourse: "Without contrary themes, individuals could neither puzzle over their social worlds nor experience dilemmas. And without this, so much thought would be impossible" (Billig et al., 1988: 2).

We provide an explanation for the strength and so the persistence of the neoliberalism version of enterprise. Some claim that the strength of enterprise is explained by its emptiness as a signifier (Jones \& Spicer, 2009; Kenny \& Scriver, 2012). However the model of enterprise discourse in dilemmatic unity with strategy offered here provides an alternative source of strength of enterprise discourse: its dilemmatic relationship with strategy means that that combined discourse can provide much to talk about while at the same time keeping that talk confined to its dilemmas. Whereas tensions between business discourse may weaken their power in other contexts (McCabe, 2008) the dilemmatic nature of Enterprise/Strategy discourse, as observed in its operation in the empirical encounters of this research, facilitates its use in generating talk that the interviewees used to achieve so many effects. The idea of a business discourse deriving strength from its dilemmatic or paradoxical nature, in the way Enterprise/Strategy has been seen to do in this research, has been raised by some scholars in management in way that supports the ideological dilemma approach of (Billig et al., 1988: 2). Oswick, Keenoy and Grant ( 2002) point to how 'oppositional dyad constructs' such as 'loose-tight' structures and 'flexible specialization' are successful because they have the power to allow new ways of thinking in the face of conventional wisdom. 
Electronic Submission ID: 16601

So our model of Enterprise/Strategy as an ideological dilemma, explains how its users can be creative while simultaneously constraining those users within the discourse that they to some extent reinforce by using. Cohen and Musson (2000:46) argue that to maintain its vitality and dynamism “...the discourse of enterprise (and any other discourse, for that matter) must not be seen as unitary, but as diverse and changeable". Neoliberalism developed enterprise by tying it to the strategy talk itself a product of the rise of corporate capitalism that had so threatened the salience of enterprise. The dilemmatic structure of the Enterprise/Strategy discourse is what allows its subtle application and variation while preserving the overall structure. There is no suggestion that humans can never escape a discourse that is structured as a dilemma. Nor is it argued that such dilemmas just constraint, rather than also empower, the individual. Rather, the claim is that in using such a discourse one is empowered to focus one's creativity within the space bounded by its dilemmas. The Enterprise/Strategy dilemma, forged by Neoliberalism, encourages us to persist in the space bounded by that limits of that ideology.

\section{REFERENCES}

Anderson, A., Drakopoulou-Dodd, S., \& Jack, S. 2009. Aggressors; Winners; Victims and Outsiders: European Schools' Social Construction of the Entrepreneur. International Small Business Journal, 27: 126-136 
Electronic Submission ID: 16601

Andrews, K. R. 1997. The Concept of Corporate Strategy. In N. J. Foss (Ed.), Resources, firms, and strategies : a reader in the resource-based perspective: 52-59. Oxford . Oxford University Press.

Ansoff, H. I. 1968. Corporate Strategy- An Analytical Approach to Business Policy for Growth and Expansion. Harmondsworth: Penguin Books.

Armstrong, P. 2005. Critique of Entrepreneurship : People and Policy. Basingstoke: Palgrave Macmillan.

Atkinson, J. M., \& Heritage, J. 1984. Transcription Notation. In J. Atkinson, \& J. Heritage (Eds.), Structures of Social Interaction: ix-xvi. New York: Cambridge University Press.

Barry, D., \& Elmes, M. 1997. Strategy Retold: Toward a Narrative View of Strategic Discourse. Academy of Management Review, 22(2): 429-452.

Billig, M., Condor, S., Edwards, D., Gane, M., Middleton, D. J., \& Radley, A. R. 1988.

Ideological dilemmas : a social psychology of everyday thinking. London: Sage.

Bögenhold, D. 2000. Limits to Mass Production: Entrepreneurship and Industrial Organization in View of the Historical School of Schmoller and Sombart. International Review of Sociology, 10(1): 57 - 71 .

Briggs, C. 2003. Interviewing,power/knowledge and social inequality. In J. Holstein, \& J. F. Gubrium (Eds.), Inside Interviewing: New Lenses, New Concerns: 495-506. Thousand Oaks: Sage. 
Electronic Submission ID: 16601

Bygrave, W. D. 2004. The Entrepreneurial Process. In W. D. Bygrave, \& A. Zacharakis (Eds.), The Portable MBA in Entrepreneurship, (3rd edition): 1-27. New York: Wiley.

Carr, P. 2000a. The age of enterprise : the emergence and evolution of entrepreneurial management. Dublin: Blackhall.

Carr, P. 2000b. Understanding enterprise culture: the 'fashioning' of enterprise activity within small business. Strategic Change, 9(7): 405-414.

Chandler, A. D. J. 1962. Strategy and Structure: Chapters in the History of American Enterprise. Cambridge: The MIT Press.

Chell, E. 2007. Social Enterprise and Entrepreneurship: Towards a Convergent Theory of the Entrepreneurial Process. International Small Business Journal, 25(1): 5-26.

Clegg, S., Carter, C., \& Kornberger, M. 2004. 'Get up, I feel like being a strategy machine'. European Management Review, 1: 21-28.

Cohen, L., \& Musson, G. 2000. Entrepreneurial Identities: Reflections from Two Case Studies. Organization, 7(1): 31-48.

Cornut, F., Giroux, H., \& Langley, A. 2012. The strategic plan as a genre. Discourse \& Communication, 6(1): 21-54.

Cox, H., \& Mowatt, S. 2008. Technological change and forms of innovation in consumer magazine publishing: a UK-based study. Technology Analysis \& Strategic Management, 20(4): $503-520$. 
Electronic Submission ID: 16601

Crouch, A., \& Basch, J. 1997. The structure of strategic thinking: A lexical and content analysis. Journal of Applied Management Studies, 6(1): 13.

Crouch, C. 2011. The strange non-death of Neoliberalism. Cambridge: Polity Press.

da Costa, A. d. S. M., \& Silva Saraiva, L. A. 2012. Hegemonic discourses on entrepreneurship as an ideological mechanism for the reproduction of capital. Organization, 19(5): 587-614.

Down, S. 2006. Narratives of Enterprise: Crafting Entrepreneurial Self-Identity in a Small Firm Cheltenham: Edward Elgar.

Drakopoulou-Dodd, S., \& Gotsis, G. 2007. Labour is holy but business is dangerous: enterprise values from the church fathers to the reformation. Journal of Enterprising Culture, 15(2): 133-163.

Duberley, J., \& Carrigan, M. 2013. The career identities of ‘mumpreneurs': Women's experiences of combining enterprise and motherhood. International Small Business Journal, 31 (6):629-651

Ensley, M. D., Carland, J.-A., \& Carland, J. W. 2000. Investigating the Existence of the Lead Entrepreneur. Journal of Small Business Management, 38(4): 59-77.

Fillis, I. A. N., \& Rentschler, R. 2010. The role of creativity in entrepreneurship. Journal of Enterprising Culture, 18(1): 49-81.

Gould, S. J. 1997. Nonoverlapping Magisteria. Natural History 106(2): 16-22.

Grandy, G., \& Mills, A. J. 2004. Strategy as Simulacra? A Radical Reflexive Look at the Discipline and Practice of Strategy. Journal of Management Studies, 41(7): 1153-1170. 
Electronic Submission ID: 16601

Hayek, F. A. 1986. The Road To Serfdom. London: Ark.

Hayton, J. C., \& Cholakova, M. 2012. The Role of Affect in the Creation and Intentional Pursuit of Entrepreneurial Ideas. Entrepreneurship: Theory \& Practice, 36(1): 41-68.

Hébert, R., F , \& Link, A. N. 2006. Historical Perspectives on the Entrepreneur . Foundations and Trends in Entrepreneurship, 2(4): 1-152.

Hendry, J. 2000. Strategic Decision Making, Discourse and Strategy as Social Practice. Journal of Management Studies, 37(7): 955-977.

Hendry, J. 2004. Cultural confusions of enterprise and the myth of the bureaucratized entrepreneur. The International Journal of Entrepreneurship and Innovation, 5(1): 5357.

Heracleous, L. 2003. Strategy and organization: Realizing strategic management. Cambridge: Cambridge University Press.

Hjorth, D. 2002. Rewriting entrepreneurship - for a new perspective on organizational creativity. Copenhagen: Copenhagen Business School Press.

Hmieleski, K. M., \& Baron, R. A. 2009. Entrepreneurs' optimism and new venture performance: a social cognitive perspective. Academy of Management Journal, 52(3): 473-488.

Hytti, U. 2005. New meanings for entrepreneurs: from risk-taking heroes to safe-seeking professionals. Journal of Organizational Change Management, 18 (6): 594-611.

Jones, C., \& Spicer, A. 2009. Unmasking the Entrepreneur. Cheltenham: Edward Elgar. 
Electronic Submission ID: 16601

Kanter, R. M. 1983. The Change Masters: Corporate Entrepreneurs at Work. London: Routledge.

Kenny, K., \& Scriver, S. 2012. Dangerously empty? Hegemony and the construction of the Irish entrepreneur. Organization, 19(5): 615-633.

Klein, P. G., Mahoney, J. T., McGahan, A. M., \& Pitelis, C. N. 2010. Toward a theory of public entrepreneurship. European Management Review, 7(1): 1-15.

Knights, D., \& Morgan, G. 1991. Corporate strategy, organizations, and subjectivity: a critique. Organization Studies, 12(2): 251-273.

Kraus, S., Harms, R., \& Schwarz, E. 2006. Strategic planning in smaller enterprises - new empirical findings. Management Research News, 29(6): 334 - 344.

Kreisler, H. 1986. A conversation with John Kenneth Galbraith In H. Kreisler (Ed.), Conversations with History. Berkeley, CA The Radio and Television Service of the University of California

Liedtka, J. M. 1998. Strategic Thinking: Can it be Taught? Long Range Planning, 31(1): 120129.

Marttila, T. 2012. The Culture of Enterprise in Neoliberalism: Specters of Entrepreneurship. London: Routledge.

McCabe, D. 2008. Who's Afraid of Enterprise?: Producing and Repressing the Enterprise Self in a UK Bank. Organization, 15(3): 371-387. 
Electronic Submission ID: 16601

Miller, K. D. 2009. Organizational Risk after Modernism. Organization Studies, 30(2-3): 157180.

Mintzberg, H. 1973. The Nature of Managerial Work. New York: Harper and Row.

Mumby, D. K. 2011. What's cooking in organizational discourse studies? A response to Alvesson and Kärreman. Human Relations, 64(9): 1147-1161.

Nicholson, L., \& Anderson, A. R. 2005. News and Nuances of the Entrepreneurial Myth and Metaphor: Linguistic Games in Entrepreneurial Sense-Making and Sense-Giving. Entrepreneurship: Theory \& Practice, 29(2): 153-173.

O'Rourke, B. K. 2010. Enterprise Discourse: Its Origins and its Influence in Ireland. In J. Hogan, P. F. Donnelly, \& B. K. O'Rourke (Eds.), Irish Business \& Society: Governing, Participating \& Transforming in the 21st Century: 69-89. Dublin: Gilll \& McMillan

O'Rourke, B. K., \& Hogan, J. 2013. Reflections in the eyes of a dying tiger: Looking back on Ireland's 1987 economic crisis In A. De Rycker, \& Z. Mohd Don (Eds.), Discourse and crisis: Critical perspectives, Vol. 52: 215-238. Amsterdam: John Benjamins.

Osborne, D., \& Gaebler, T. 1993. Reinventing Government : How the Entrepreneurial Spirit is Transforming the Public Sector. London: Plume.

Oswick, C., Keenoy, T., \& Grant, D. 2002. Metaphor and analogical reasoning in organization theory: Beyond orthodoxy. Academy of Management Review, 27(2): 294-303. 
Electronic Submission ID: 16601

Pälli, P., Vaara, E., \& Sorsa, V. 2009. Strategy as text and discursive practice: a genre-based approach to strategizing in city administration. Discourse \& Communication, 3(3): 303318.

Perren, L., \& Jennings, P. L. 2005. Government Discourses on Entrepreneurship: Issues of Legitimization, Subjugation, and Power. Entrepreneurship: Theory \& Practice, 29 ( 2): 173--185.

Pitt, M. 1998. A Tale of Two Gladiators: 'Reading' Entrepreneurs as Texts. Organization Studies, 19(3): 387-414.

Porter, M. E. 1996. What Is Strategy? Harvard Business Review, 74( 6): 61-78.

Quinn, R. E. 1988. Beyond Rational Management: Mastering the Paradoxes and Competing Demands of High Performance. San Francisco: Jossey-Bass.

Rose, N. 1992. Governing the enterprising self. In P. Heelas, \& P. Morris (Eds.), The values of the enterprise culture : the moral debate: 141-164. London: Routledge.

Rutherford, B. A. 2005. Genre Analysis of Corporate Annual Report Narratives: A Corpus Linguistics-Based Approach. Journal of Business Communication, 42(4): 349-378.

Samra-Fredericks, D. 2003. Strategizing as Lived Experience and Strategists' Everyday Efforts to Shape Strategic Direction. Journal of Management Studies, 40(1): 141-174.

Sarasvathy, S. D., \& Venkataraman, S. 2011. Entrepreneurship as Method: Open Questions for an Entrepreneurial Future. Entrepreneurship Theory \& Practice, 35 (1): 113-135. 
Electronic Submission ID: 16601

Schumpeter, J. A. 1976. Capitalism, socialism and democracy (5th ed.). London: Allen and Unwin.

Vaara, E., Sorsa, V., \& Pälli, P. 2010. On the force potential of strategy texts: a critical discourse analysis of a strategic plan and its power effects in a city organization. Organization, 17 (6): 685-702.

Van der Wurff, R. 2005. Business Magazine Market Performance: Magazines for the Agricultural, Business Services, and Transportation Sectors in the Netherlands. Journal of Media Economics, 18(2 ): 143-159.

White, R. E., Thornhill, S., \& Hampson, E. 2006. Entrepreneurs and evolutionary biology: The relationship between testosterone and new venture creation. Organizational Behavior and Human Decision Processes, 100(1 ): 21-34

Whittle, A., \& Mueller, F. 2011. The language of interests: The contribution of discursive psychology. Human Relations, 64(3): 415-435.

Wirtz, B. W. 2011. Media and interner management. Wiesbaden: Gabler Verlag.

\section{APPENDIX A: THE JEFFERSON-STYLE TRANSCRIPTION NOTATION USED}

Symbol Meaning

A stopping fall in tone firmly understood as a full stop

A brief pause understood as a comma 
Electronic Submission ID: 16601

- $\quad$ Indicates a sudden stop understood as breaking with previous sense

(.) A brief but noticeable pause.

(\# ) A timed paused where \# is the number of seconds

$\downarrow \quad$ A falling tone

? A rising inflection understood as a question

$\uparrow \quad$ A rising inflection not understood as a question

$>$ text $<$ enclosed speech was delivered more quickly than usual

$<$ text $>$ enclosed speech was delivered more slowly than usual

.. Deliberated excluded talk within a turn

[text] Square brackets enclose overlapping speech

ALL CAPS Shouted or increased-volume speech

Underlined text Speaker is stressing the underlined speech.

( text ) Enclosed is transcriber's best guess of unclear speech.

$(($ text $))$ Enclosed is a report of non-verbal activity, deliberate replacement or larification.

Note This transcription notation is based on the notation developed by Gail Jefferson as described in Atkinson and Heritage (1984). 